\title{
Effects of acute gamma radiation on the reproductive ability of the earthworm Eisenia fetida
}

\author{
K. Sowmithra ${ }^{\text {a }}$, N.J. Shetty ${ }^{\text {a, }}{ }^{*}$, B.P. Harini ${ }^{\text {a }}$, S.K. Jha ${ }^{\text {b }}$, R.C. Chaubey ${ }^{\text {b }}$ \\ a Centre for Applied Genetics, Bangalore University, JB Campus, Bangalore, Karnataka 560056, India \\ ${ }^{\mathrm{b}}$ BRNS-DAE, Bhabha Atomic Research Centre, Mumbai 400085, India
}

\section{A R T I C L E I N F O}

Article history:

Received 13 December 2013

Received in revised form

30 September 2014

Accepted 16 October 2014

Available online 25 November 2014

\section{Keywords:}

Eisenia fetida

Gamma radiation

Cocoon

Hatchling

Seminal vesicle

\begin{abstract}
A B S T R A C T
Earthworms are the most suitable biological indicators of radioactive pollution because they are the parts of nutritional webs, and are present in relatively high numbers. Four months old Eisenia fetida were exposed to different doses of gamma radiation, namely $1,2,3,5,10,15,20,25,30,35,40,45,50,55$ \& $60 \mathrm{~Gy}$ to study the effects of radiation on different reproductive parameters. The number of cocoons laid and the hatchlings emerged were recorded for all the selected doses. There was no reduction in cocoon production, however; decreasing size and weight of the cocoons was observed from the samples exposed to $20 \mathrm{~Gy}$ and above doses. Significant reductions in the hatchlings were recorded in earthworms exposed to $10 \mathrm{~Gy}$ and above doses. The dose response curves for a percentage reduction in hatchlings were constructed. Exposure to radiation dose of 1 and $2 \mathrm{~Gy}$ did not show any reduction, however, there was $\approx 10 \%, \approx 50 \%$ and $\approx 90 \%$ decrease in the hatchlings in samples exposed to 3,15 and $45,50,55$ and 60 Gy doses respectively. Delayed hatchability was also reported at al exposure level. Histology of irradiated earthworms revealed that the structural damage in the seminal vesicles was prominent at the exposed dose of $3 \mathrm{~Gy}$ onwards with complete degeneration on exposure to $60 \mathrm{~Gy}$ of gamma radiation.
\end{abstract}

๑) 2014 Elsevier Ltd. All rights reserved.

\section{Introduction}

In nature radioactive material occurs either as naturally in the form of radioactive isotopes in rocks or as a consequence of human release such as during nuclear testing, normal maintenance of nuclear power plants and nuclear accidents such as those at Chernobyl and Fukushima Dallchi. Natural level of radiation sometime exceeds low baseline levels in uncontaminated areas by several hundred folds, resulting in significant rates of diseases in human and other organisms and also causes reproductive failure (Lubin and Boice, 1997; Ghiassi-Nejad et al., 2002).

Reproduction is considered to be among the most sensitive radiation-associated end points (UNSCEAR, 1996), and it not only determines the fate of the single organism, but also influence the population dynamics and the stability of higher ecological units. Although many tissues show negligible damage, the reproductive organs are very sensitive to gamma radiation because the germ cells usually show moderate to severe damage. The rapidly dividing germ cells that are still in the process of differentiation are

\footnotetext{
* Corresponding author. Tel.: +91 80 22961301, +91 8023212318.

E-mail address: shetty_nj@yahoo.co.in (N.J. Shetty).
}

particularly radiosensitive, and because of their active division they express radiation damage quickly (Tilton and Brower, 1983).

As atomic power is increasingly recognized as a potential energy source to sustain future human development, radiological protection of the environment will become an even more important environmental safety concern (ICRP, 2003). In the past decades, scientific and regulatory activities related to radiation protection has been focused on the radiation exposure on humans. The prevailing view has been that, if humans were adequately protected, then other living things are also likely to be sufficiently protected or other species are not put at risk (ICRP, 1991). Over the time, the general validity of this view has been questioned on several occasions and therefore, consideration has been given to the potential effects of exposure to ionizing radiation of non-human biota. Thus, an understanding of the effects of ionizing radiation on non-human biota is requisite by the International Commission on Radiological Protection (ICRP) for the radiological protection of the environment (ICRP, 2003).

In most contamination situations, the majority of the radionuclide inventory in terrestrial ecosystems is found within the soil; thus soil invertebrates can receive significant external and internal doses (Agüiero et al., 2001). Soil animals have a more important role to play in the accumulation and migration of radionuclides and 
earthworms are the organism that are most sensitive to the radionuclides, probably because intimate contact they have with soil constituents in the upper soil layers (Krivolutsky, 1987). Earthworms are apt subjects for the assessments due to the potential role they play in vermi-composting and nutrient cycling and also because they constitute up to $92 \%$ of the invertebrate biomass in the soil. They are some of the most suitable animals which can act as a key bioindicator for testing the toxicity of chemicals in soils (Callahan, 1988; Goats and Edwards, 1988; Bouche, 1992). Furthermore, among the various earthworm species, E. fetida is especially appropriate for the toxicity tests because it can be easily bred on a variety of organic wastes with short generation times. They have also been adopted as standard organisms for ecotoxicological testing by the European Union (EEC, 1984); OECD (1984, 2000) and included in the list of reference animal and plants (RAP) of the International Commission on Radiological Protection (ICRP, 2008) and as a candidate reference organism from Framework for Assessment of Environmental Impact (Agüero et al., 2001) to study the harmful effect of ionizing radiation.

Much of the data concerning the effects of radiation on earthworms are derived from field studies in which, radionuclide activities in soil have been increased by artificial contamination or by field monitoring after nuclear accidents. These studies have shown effects such as reduced population size, changes in the distribution of life cycle stages, and reduced number of species. Hertel-Aas et al. (2007) and Nakamori et al. (2009) studied the effect of chronic and acute gamma radiation respectively on E. fetida, and found that gamma irradiation reduces the reproductive ability of the E. fetida. By keeping this information as a benchmark, an attempt has been made to perceive the consequences of gamma radiation on the reproductive ability and also on the seminal vesicles of the E. fetida after exposed to different doses of acute gamma radiation.

\section{Materials and methods}

\subsection{Culturing of E. fetida}

E. fetida were obtained from the University of Agricultural Science, Gandhi Krishi Vignana Kendra, Bangalore. The age synchronized worms were maintained according to the procedure of Yasmin and D'Souza, (2007) with slight modification. The mixture contained $75 \%$ soil and $25 \%$ cow dung for the culture of worms. The dry black soil was powdered and filtered through a fine mesh sieve. The sieved soil was then moistened, and 25 adult worms were transferred to it. The air dried cow dung, was supplemented as food, and the culture was covered with wet cloth. After 30 days, the adult worms were removed from the system. During the period of 30 days in the culture, the worms reproduced and lay cocoons. Once the worms were removed, the culture was left undisturbed for 4 months. Water was sprinkled to keep the soil moist. After 4 months, worms of the same age were obtained from the culture. This age synchronized worms were used for the experiment.

\subsection{Radiation experiment}

Standardized tests using earthworms have been developed according to the Organization for Economic Co-operation and Development (OECD, 2000) and similar protocols were used for assessing radiation effects. Four months old earthworms were placed in glass containers with a little amount of water and allowed to defecate for a day. A group of twenty worms (average wet weight $400 \mathrm{mg}$ ) was transferred to a plastic petri dish with moist filter paper and then irradiated with 1, 2, 3, 5, 10, 15, 20, 25, 30, 35, 40, 45, 50,55 and 60 Gy radiation using $\mathrm{Co}^{60}$ gamma radiation source (Theratron $780-C$ machine) with a dose rate of $146.75 \mathrm{CGy} / \mathrm{min}$
(The exposure time ranges from $0.68 \mathrm{~min}$ ( $1 \mathrm{~Gy}$ ) to $40.88 \mathrm{~min}$ (60 Gy) and the distance between the source and the object was $80 \mathrm{~cm}$ ). After irradiation, pair of worms was placed in each plastic test container ( $11 \mathrm{~cm}$ diameter) provided with air dried cow dung as food. Non irradiated earthworms were used as control. Moisture content in the test vessels was maintained (60-80\%) by sprinkling water every alternate day. A month after irradiation, numbers of cocoons laid were counted and weighed (approximately 15 days after the cocoon laid). The adult worms were removed from the soil and placed in fresh cultures. Two months after irradiation, the number of offspring (hatched from the cocoons) in the soil was examined by hand picking method. Ten replicates were used for each treatment.

The statistical analysis was carried out using one-way ANOVA and Tukey HSD test was performed to determine exactly which doses affected most significantly from the control group.

\subsection{Histopathology studies}

Worms from the control and the irradiated samples $(1,2,3,5,10$, $20,30,40$ and $50 \mathrm{~Gy}$ ) were subjected to histopathological studies of the reproductive organs $(n=10)$. Histopathology was carried out according to the procedure of Hertle-Aas et al. (2007). Immediately after irradiation worms were transferred to water for $24 \mathrm{~h}$ to defecate the gut content from the anterior part. Worms were then anesthetized in $12 \%$ ethanol and fixed in $10 \%$ formalin fixative for $24 \mathrm{~h}$ at room temperature followed by $70 \%$ ethanol. Individuals were cut between 8th and 16th segments. Resulting segments containing the reproductive organs were then dehydrated by passing through ascending grades of alcohol, cleared in xylene, infiltrated with molten paraffin, and finally embedded in paraffin wax ( $58^{\circ} \mathrm{C}$ MP). 5 - $\mu \mathrm{m}$ thick transverse sections of tissue were obtained using a rotary microtome. The sections were then stained in Harris haematoxylin and eosin $(\mathrm{H} \& \mathrm{E})$ stain, dehydrated using alcohol, kept in xylene to clear the excess stains and finally mounted using dihydroxy phthalate xylol (DPX). The stained slides were observed in the compound microscope (Leitz DIALUX 22, Germany).

\section{Results and discussion}

\subsection{Cocoon}

No significant reduction in the cocoon productions was observed in exposed samples (Table 1). Our observation was similar to that of Hertel-Aas et al. (2007) and Suzuki and Egami (1983) were cocoon production of E. fetida exposed to different doses of gamma radiation were unaffected. Even though there was no reduction in the number of cocoons laid, cocoons obtained from the irradiated samples showed reduction in size, mass (Table 2) and change in the external morphology (Fig. 1). There was a significant difference in the mass of the cocoons exposed to $20 \mathrm{~Gy}$ and above doses $(F=41.391 ; d f=15,304 ; P<0.05)$. This may be envisaged due to the fewer number of hatchlings inside the cocoon.

\subsection{Hatchlings}

There was no significant reduction found in the hatchlings of the F1 generation whose parent was exposed to $1,2,3$ and $5 \mathrm{~Gy}$, however reduction in the hatchlings was recorded in the $\mathrm{F} 1$ generation of $10 \mathrm{~Gy}(F=61.842 ; d f=15,144 ; P<0.05)$ radiated sample. There was $\approx 10 \%, \approx 50 \%$ and $\approx 90 \%$ reduction in the hatchlings found in the samples exposed to $3 \mathrm{~Gy}, 15 \mathrm{~Gy}$ and 45, 50, 55 and 60 Gy doses respectively (Fig. 2). This is well supported by the histological data where the degradation of seminal vesicles (SV) 
Table 1

Total number of cocoons laid and hatchlings produced from the earthworms exposed to different doses of gamma radiation.

\begin{tabular}{llc}
\hline Doses (Gy) & Cocoon \pm SE & Hatchlings \pm SE \\
\hline Control & $42 \pm 0.07$ & $141 \pm 0.57$ \\
1 & $41 \pm 0.31$ & $132 \pm 0.84$ \\
2 & $40 \pm 0.37$ & $128 \pm 0.95$ \\
3 & $41 \pm 0.31$ & $125 \pm 0.91$ \\
5 & $39 \pm 0.31$ & $120 \pm 1.00^{*}$ \\
10 & $38 \pm 0.33$ & $77 \pm 0.67^{*}$ \\
15 & $38 \pm 0.29$ & $63 \pm 0.56^{*}$ \\
20 & $40 \pm 0.39$ & $57 \pm 0.47^{*}$ \\
25 & $41 \pm 0.53$ & $41 \pm 0.53^{*}$ \\
30 & $39 \pm 0.40$ & $27 \pm 0.40^{*}$ \\
35 & $34 \pm 0.74$ & $18 \pm 0.74^{*}$ \\
40 & $35 \pm 0.27$ & $15 \pm 0.56^{*}$ \\
45 & $37 \pm 0.34$ & $11 \pm 0.50^{*}$ \\
50 & $44 \pm 0.27$ & $10 \pm 0.47^{*}$ \\
55 & $46 \pm 0.34$ & $11 \pm 0.35^{*}$ \\
60 & $49 \pm 0.38$ & $10 \pm 0.39^{*}$ \\
\hline
\end{tabular}

SE $=$ Standard error, ${ }^{*}$ Significant different from control.

started showing at $3 \mathrm{~Gy}$ and very conspicuous in $10 \mathrm{~Gy}$ and above doses. Most of the samples exposed to 50 and $60 \mathrm{~Gy}$ radiation showed completely atrophied (CA) seminal vesicles (Fig. 3). Spermatheca seems to be not affected by the radiation. The most likely mechanism for the reduction in hatchability may be that the damage is induced directly in male germ cells, i.e. spermatogenic cells or due to accumulation of damage in the testes and seminal vesicles. This could result in infertile sperm or a reduced or total lack of sperm production (Hertle-Aas et al., 2007). It was observed that the percentage reduction in hatchling remained constant in test samples exposed to 45, 50, 55 and 60 Gy radiation doses. Even though the reproduction was low in these doses; reproduction seemed to be maintained at the reduced level, which could be indicating acclimatization or stabilization. In E. fetida, the first spermatogonial divisions occur in the testis. When the spermatogonial morula has reached the 8-32-cell stage, it leaves the testes and further spermatogonial divisions and spermiogenesis take place in the seminal vesicles (Suzuki and Egami, 1983, 1984). The mature spermatozoa then pass to the seminal funnels, where they remain until copulation occurs. During mating they pass through the vas efferens and the vas deferens to the exterior through the two male pores in segment 15 and stored in the spermatheca of the recipient (Edwards and Bohlen, 1996). Although spermatogenesis has ceased, fertilization takes place by using sperms which are stored in the spermatheca after the copulation. Delayed

Table 2

Weight of the cocoons from the samples exposed to different doses of gamma radiation.

\begin{tabular}{ll}
\hline Dose $(\mathrm{Gy})$ & Weight of the cocoons $\pm \mathrm{SE}$ \\
\hline Control & $20.5 \pm 0.2$ \\
1 & $21.0 \pm 0.2$ \\
2 & $20.2 \pm 0.3$ \\
3 & $20.5 \pm 0.2$ \\
5 & $21.2 \pm 0.2$ \\
10 & $21.1 \pm 0.3$ \\
15 & $20.8 \pm 0.2$ \\
20 & $17.0 \pm 0.3^{*}$ \\
25 & $16.2 \pm 0.3^{*}$ \\
30 & $17.5 \pm 0.4^{*}$ \\
35 & $17.1 \pm 0.3^{*}$ \\
40 & $16.9 \pm 0.3^{*}$ \\
45 & $16.5 \pm 0.3^{*}$ \\
50 & $16.2 \pm 0.2^{*}$ \\
55 & $17.5 \pm 0.4^{*}$ \\
60 & $16.0 \pm 0.2^{*}$ \\
\hline
\end{tabular}

$\mathrm{SE}=$ Standard error, ${ }^{*}$ Significant different from control.

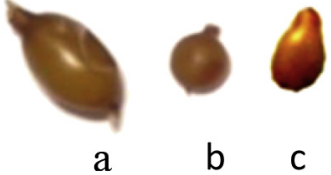

Fig. 1. a) Cocoon of normal size and shape. b) Cocoon of reduced size. c) Change in shape.

hatchability was observed in the samples exposed to all the above doses. Unhatched cocoons were dissected, and were found to be non-embryonated. Hasan (1995) noticed that high doses of gamma radiation in beetles Tribolium anaphe can inactivate sperm or produce dominant lethals in cells and lower doses can have significant effects on sperm production, especially if the timing of the treatment has affected the developing sperm cells. Cells in the process of spermatogenesis are very radiosensitive and apparently are easily killed (Hasan et al., 1989).

Comparison between the earthworm reproduction data of both acute and chronic gamma radiation of the present study and earlier study, it was observed that the sensitivity of the reproduction to acute gamma radiation was higher than that of chronic irradiation. In external chronic exposure tests, the hatchability of cocoons produced during the first 4 weeks decreases by $61 \%$ at $43 \mathrm{mGy} / \mathrm{h}$ i.e accumulated dose of $26 \mathrm{~Gy}$ (Hertel-Aas et al., 2007). The ED 50 for reproduction with acute irradiation was approximately half of the accumulated dose, i.e $10 \mathrm{~Gy}$, which is almost similar to the data of Nakamori et al. (2009) at $11 \mathrm{~Gy}$ and slightly lower than the value of Suzuki and Egami (1983) i.e 2 kR (17.2 Gy). In general, dose rates used in the laboratory are higher than exposures in the nature. At sites contaminated by regulating the release of radionuclides, existing assessments indicate that the absorbed dose rates are usually no more than $0.1 \mathrm{mGy} / \mathrm{h}$ and always less than $1 \mathrm{mGy} / \mathrm{h}$ (Woodhead, 2004). However, there are few circumstances after the nuclear accident in which, dose rates in nature may be much greater than the normal. For example, in case of the Chernobyl accident, where the dose absorbed by earthworms was reported to be $86 \mathrm{~Gy}$ during the initial few months in the 3-km zone around the reactor (Krivolutzkii and Pokarzhevskii, 1992) which affected the earthworm population as well as changes in the composition of the population. UNSCEAR has also reported that in Mayak, the total density and biomass of soil organisms were still depressed even 30 years after the accident (UNSCEAR, 1996). Field studies from former Soviet Union sites have reported that extensive damage happened to the eggs and larva of invertebrates at $4-40 \mathrm{mGy} / \mathrm{h}$ (Sazykina, 2005) and on earthworms at lower exposure levels, i.e., $100 \mu \mathrm{Gy} /$ $\mathrm{h} \alpha-$ particle radiation (UNSCEAR, 1996).



Fig. 2. Percentage reduction in the hatchlings of the F1 generation on exposure to different doses of gamma radiation. 

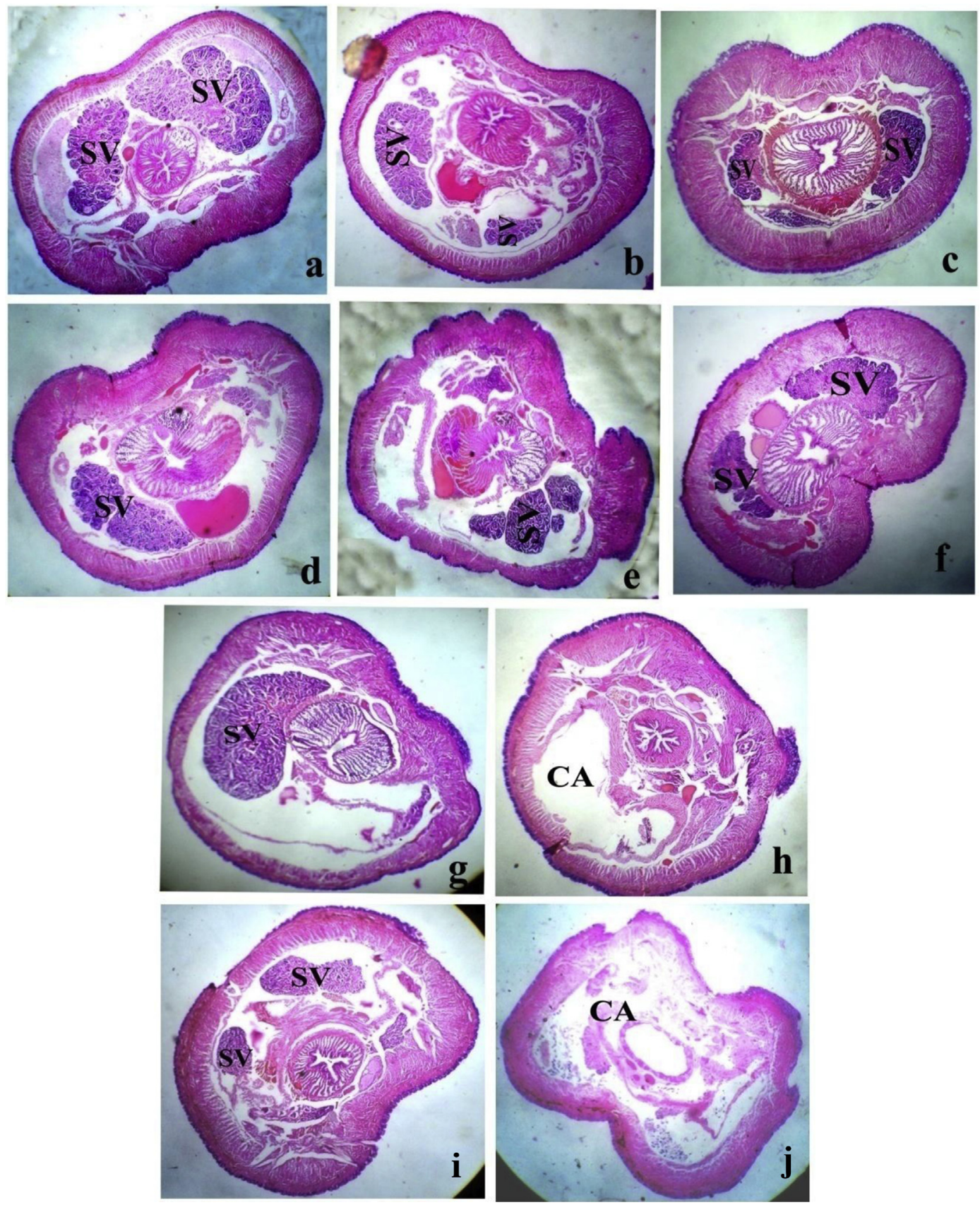

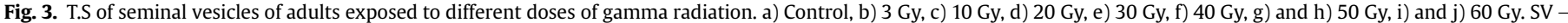
Seminal vesicle, CA - Completely atrophied.

\section{Conclusion}

Our study clearly shows the effect of acute gamma radiation on the reproductive ability of $E$. fetida, especially on the hatchability. In addition to this, histological evidence reveals that the seminal vesicles are more susceptible to radiation and results in degradation with the increase in radiation dose. Thus, the study establishes important baseline data for the radiological protection of terrestrial ecosystems and also supports the result of earlier studies (Hertle-Aas et al., 2007; Suzuki and Egami, 1983) that the reduction in hatchling production is due to the radiosensitivity of the seminal vesicles during the process of development of sperm cells which leads to the abnormal sperms and thus affects the fertilization.

\section{Acknowledgements}

This work was supported by grants of Board of Research in Nuclear Science (BRNS) - Department of Atomic Energy (DAE) and Bhabha Atomic Research Centre (BARC), Mumbai (No. 2009/36/80BRNS/2394 dated 9/12/2009). We wish to thank to the radiation physics department of the KIDWAI Memorial Institute of Oncology, Bangalore for providing radiation facility.

\section{References}

Agüero, A., Barnett, C.L., Brown, J., Gilek, M., Howard, B.J., Ilus, E., Kautsky, U., Kumblad, L., Naeslund, B., Wright, S.M., 2001. Identification of candidate reference organisms from a radiation exposure pathways perspective, deliverable 1. In: Strand, P., Beresford, N., Avila, R., Jones, S.R., Larsson, C.M. (Eds.), 
FASSET, Framework for Assessment of Environmental Impact. European Community, Luxembourg, pp. 1-48.

Bouche, M.B., 1992. Earthworm species and ecotoxicological studies. In: GreigSmith, P.W., Becker, H., Edwards, P.J., Heimbach, F. (Eds.), Ecotoxicology of Earthworms, pp. 20-35. Intercept, Andover.

Callahan, C.A., 1988. Earthworms as ecotoxicological assessment tools. In: Edwards, C.A., Neuhauser, E.F. (Eds.), Earthworms in Waste and Environmental Assessment. SPB Academic, The Hague, pp. 295-301.

Edwards, C.A., Bohlen, P.J., 1996. Biology and Ecology of Earthworms. Chapman \& Hall, London.

EEC (European Economic Community), 1984. Directive 79/831/EEC, Annex V, Part C. Method for the Determination of Ecotoxicity. Level 1. Earthworms: artificial soi test. Commission of the European Communities, Brussels. DGXI/128/82. Rev. 5.

Ghiassi-Nejad, M., Mortazavi, S.M.J., Cameron, J.R., Niroomand-rad, A., Karam, P.A. 2002. Very high background radiation areas of Ramsar, Iran: preliminary biological studies. Health Phys. 82, 87-93.

Goats, G.C., Edwards, C.A., 1988. The prediction of field toxicity of chemicals to earthworms by laboratory methods. In: Edwards, C.A., Neuhauser, E.F. (Eds.) Earthworms in Waste and Environmental Assessment. SPB Academic Publishing, The Hague, Netherlands, pp. 283-294.

Hasan, M., Khalequzzaman, M., Khan, A.R., 1989. Development of Tribolium anaphe irradiated as larvae of various ages with gamma rays. Entomol. Exp. Appl. 53, $92-94$

Hasan, M., 1995. Comparative Sensitivity of Tribolium spp., to Gamma Irradiation throughout Ontogeny. Unpubl. Ph. D. thesis. University of Newcastle Upon Tyne UK.

Hertel-Aas, T., Oughton, D.H., Jaworska, A., Bjerke, H., Salbu, B., Brunborg, G., 2007. Effects of chronic gamma irradiation on reproduction in the earthworm Eisenia fetida (Oligochaeta). Radiat. Res. 168, 515-526.

ICRP., 1991. Recommendations of the International Commission on Radiologica Protection. In: Publication 60, vol. 21. Ann. ICRP, pp. 1-3.

ICRP, 2003. A Framework for Assessing the Impact of Ionizing Radiation on Nonhuman Species. In: Publication 91, vol. 33. Ann. ICRP.
ICRP, 2008. Environmental Protection: the Concept and Use of Reference Animals and Plants. In: Publication 108, vol. 38. Ann. ICRP, pp. 4-6.

Krivolutsky, D.A., 1987. In: Striganova, B.R. (Ed.), Radiation Ecology of Soil Animals. Biol. Fertil. Soils, Nauka., Moscow, pp. 51-55.

Krivolutzkii, D.A., Pokarzhevskii, A.D., 1992. Effects of radioactive fallout on soil animal populations in the $30 \mathrm{~km}$ zone of the Chernobyl atomic power station. Sci. Total Environ. 112, 69-77.

Lubin, J.H., Boice Jr., J., 1997. Lung cancer risk from residential radon: meta-analysis of eight epidemiologic studies. J. Natl. Cancer Inst. 89, 49-57.

Nakamori, T., Kubota, Y., Ban-nai, T., Fujii, Y., Yoshida, S., 2009. Effects of acute gamma irradiation on soil invertebrates in laboratory tests. Radioprotection 44 421-424.

OECD, 1984. Earthworm, acute toxicity tests. In: Organization for Economic Cooperation and Development. OECD guidelines for testing of chemicals, Paris.

OECD, 2000. Guidelines for testing of chemicals. In: Earthworm Reproduction Test (Eisenia fetida/andrei). OECD, Paris.

Sazykina, T.G., 2005. A system of dose-effects relationships for the northern wildlife: radiation protection criteria. Radioprotection 40 (suppl. 1), 889-892.

Suzuki, J., Egami, N., 1983. Mortality of the earthworms, Eisenia-fetida, after gammairradiation at different stages of their life-history. J. Radiat. Res. 24, 209-220.

Suzuki, J., Egami, N., 1984. Radiation-induced damage and recovery from it in germ cells in the earthworm, Eisenia foetida. J. Fac. Sci. Univ. Tokyo., Sec. IV Zool. 15, 329-342.

Tilton, E.W., Brower, J.H., 1983. Radiation effect on arthropods. In: Josephson, E.S., Peterson, M.S. (Eds.), Preservation of Food by Ionizing Radiation. CRC Press, Florida, pp. 269-316.

UNSCEAR, 1996. Sources and effects of ionizing radiation. In: Report to the General Assembly, with Scientific Annex United Nations, New York, pp. 1-86.

Woodhead, D., 2004. Environmental Dosimetry, Protecting Biota from Ionizing Radiation. The Society of Radiological Protection, London, pp. 1-6.

Yasmin, S., D'Souza, D., 2007. Effect of pesticides on the reproductive output of Eisenia fetida. Bull. Environ. Contam. Toxicol. 79, 529-532. 